\title{
Article \\ Silica-Based Composites with Enhanced Rheological Properties Thanks to a Nanosized Graphite Functionalized with Serinol Pyrrole ${ }^{\dagger}$
}

\author{
Gea Prioglio ${ }^{1}$, Silvia Agnelli ${ }^{2}$ (D), Stefano Pandini ${ }^{2}$ and Maurizio Galimberti ${ }^{1, *(D)}$ \\ 1 Department of Chemistry, Materials and Chemical Engineering Giulio Natta, Politecnico di Milano, \\ Via Mancinelli 7, 20131 Milano, Italy; gea.prioglio@polimi.it \\ 2 Department of Mechanical and Industrial Engineering, University of Brescia, Via Branze 38, \\ 25123 Brescia, Italy; silvia.agnelli@unibs.it (S.A.); stefano.pandini@unibs.it (S.P.) \\ * Correspondence: maurizio.galimberti@polimi.it \\ $+\quad$ The hybrid silica/HSAG-SP materials studied in this work could be used in rubber compounds for \\ dynamic-mechanical applications such as the ones for tires.
}

check for updates

Citation: Prioglio, G.; Agnelli, S.; Pandini, S.; Galimberti, M. Silica-Based Composites with Enhanced Rheological Properties Thanks to a Nanosized Graphite Functionalized with Serinol Pyrrole. Appl. Sci. 2021, 11, 11410. https:// doi.org/10.3390/app112311410

Academic Editor: Valentino Paolo Berardi

Received: 22 October 2021 Accepted: 30 November 2021 Published: 2 December 2021

Publisher's Note: MDPI stays neutral with regard to jurisdictional claims in published maps and institutional affiliations.

Copyright: (c) 2021 by the authors. Licensee MDPI, Basel, Switzerland. This article is an open access article distributed under the terms and conditions of the Creative Commons Attribution (CC BY) license (https:/ / creativecommons.org/licenses/by/ $4.0 /)$.

\begin{abstract}
Silica-based rubber composites have tremendous importance, as they allow the reduction in hysteresis in demanding dynamic-mechanical applications such as tire compounds and hence have a lower environmental impact. However, they also present drawbacks such as poor rheological behavior. In this work, an innovative silica-based hybrid filler system was developed, obtaining a rubber composite with an improved set of properties. A nanosized high surface area graphite (HSAG) was functionalized with 2-(2,5-dimethyl-1H-pyrrol-1-yl)propane-1,3-diol, serinol pyrrole (SP), through a simple process characterized by a high carbon efficiency. The HSAG-SP adduct, with about nine parts of SP per hundred parts of carbon filler, was used to form a hybrid filler system with silica. An elastomeric composite, with poly(styrene-co-butadiene) from anionic polymerization and poly(1,4-cis-isoprene) from Hevea brasiliensis was prepared with 50 parts of silica, which was replaced in a minor amount $(15 \%)$ by either pristine HSAG or HSAG-SP. The best set of composite properties was obtained with HSAG-SP: the same dynamic rigidity and hysteresis and tensile properties of the silica-based material and appreciably better rheological properties, particularly in terms of flowability. This work paves the way for a new generation of silica-based composites, with improved properties, based on a hybrid filler system with a nanosized edge functionalized graphite.
\end{abstract}

Keywords: silica; functionalized nanographite; rheological properties

\section{Introduction}

Toward the end of the last century, silica revolutionized the field of elastomer composites, becoming the preferred reinforcing filler for large scale highly demanding dynamicmechanical applications such as tire compounds. Indeed, silica, with respect to carbon black, enables a reduction in hysteresis, thus, in dissipation of energy and impact on the environment.

Silica has a polar surface, rich in oxygen atoms and characterized by silanol and siloxane functional groups [1]. The silica used in elastomer composites for tires is in precipitated form [1,2] and has a high surface area and surface activity. As a consequence, silica tends to create filler networks and its dispersibility in apolar elastomer matrices, typical of most elastomer composites and in particular of tire composites, is very poor [3]. The compatibilization of precipitated silica with hydrocarbon elastomers is obtained by using the so-called coupling agents, molecules such as organosilanes containing sulphur atoms, which react with silanols during the compounding step, leading to the hydrophobization of the silica surface, and with the unsaturated polymer during the sulphur-based crosslinking step [3-5], establishing a filler-elastomer covalent bond. The reduction in hysteresis of the 
elastomeric composites is due to the chemical linkage between silica and the elastomer chains. A typical organosilane is bis(triethoxysilylpropyl)tetrasulfide (TESPT). The technology based on precipitated silica is developed at the industrial scale and has been used to produce billion of tires. However, it has drawbacks. The reaction of silica with the organosilane TESPT releases ethanol, which has to be burned in the industrial plants, with a negative impact on the sustainability of the process. Silica is difficult to process and is corrosive. Special compounding equipment has to be used and replaced with troublesome frequency. Silica also leads to the increase in the compound viscosity and drastically reduces the shelf life of the semi-finished products. Moreover, due to its acidic nature, composites hardly achieve a plateau value of the highest modulus $\left(\mathrm{M}_{\mathrm{H}}\right)$ in vulcanization, exhibiting the so-called phenomenon of marching modulus, which has negative effects on the efficiency and reproducibility of vulcanization, also at the industrial scale. It would be thus highly desirable to substitute or at least to partially replace silica with an alternative filler, maintaining the same composite dynamic mechanical properties and eliminating or at least reducing the mentioned drawbacks. The alternative filler should have functional groups able to establish a chemical bond with the elastomer chains and/or to create a hybrid network with silica. The hybrid network should promote less filler networking than silica and, as a consequence, should favor lower compound viscosity. A lower acidity, with respect to silica, is also desirable to have more efficient vulcanization.

The objective of this work was the partial replacement of silica with a nanosized $\mathrm{sp}^{2}$ carbon allotrope. Nanosized graphite with a high surface area and high shape anisotropy (HSAG) [6] was chosen. The nano size was selected to have a high interfacial area with the polymer matrix and, thus, great efficiency at low filler content. The carbon allotrope was selected as it was expected to substantially reduce the abovementioned drawbacks arising from silica: indeed, it has lower surface activity and acidity. Papers on rubber composites with graphene and related materials (GRM), mainly based on isoprene rubber, are available in the scientific literature [7-12]. The main objective of these researchers was to achieve an ultimate distribution and dispersion of the GRM. The main outcome of the papers is the rational design of the surface chemistry of the filler [10]. In most cases, latex dispersions were prepared with polar graphitic materials, such as graphene oxide, known as GO $[7,8,10,11,13-18]$. HSAG is characterized by a low number of stacked layers, in a crystalline domain, and by a high crystalline order inside a single basal plane. Studies performed by the authors on HSAG have been reported elsewhere [19-26]. In order to promote the compatibility with silica and the reactivity with the elastomer chains (through a coupling agent), HSAG was functionalized with $\mathrm{OH}$ groups (HSAG-OH). A reaction was performed between HSAG and a pyrrole compound, serinol pyrrole (SP). Some of the authors reported that a pyrrole compound, such as SP, is able to react with the edges of graphene layers [19-26]. The functionalization reaction is characterized by a high atom efficiency and occurs through a domino mechanism [26]: the pyrrole compound undergoes a carbocatalyzed oxidation in the benzylic position and gives rise to a cycloaddition reaction with the carbon substrate. The $\mathrm{OH}$ groups could also be reactive with the silane (e.g., TESPT), and thus, they could promote the chemical bond with the elastomer.

HSAG-OH was characterized, determining the thermal stability and the amount of the organic modifier. The efficiency of the functionalization reaction was estimated. Elastomer composites based on poly(styrene-co-butadiene) rubber from anionic solution polymerization (S-SBR) and poly(1,4-cis-isoprene) from Hevea brasiliensis (natural rubber, NR) were prepared. Silica was used as the filler. A minor amount of silica, $15 \%$ by volume, was replaced with either HSAG or HSAG-OH, maintaining the same volume fraction of the filler. Crosslinking was performed with a sulphur-based system. Tensile properties were studied through quasistatic measurements. Dynamic mechanical properties were measured both in the shear and in the axial mode. Some of the authors have shown that nanocarbon allotropes, such HSAG and CNTs, in particular, give rise to elastomer composite materials whose properties are directly dependent on the used carbon allotrope. The anisotropic mechanical behavior of the systems was investigated by means of DMA 
tests, performed on specimens taken from plates in shear-sandwich configuration. The rheological properties were studied by measuring the Mooney viscosity and by means of high pressure capillary viscosimeter (HKV) tests.

\section{Materials and Methods}

\subsection{Materials}

High surface area graphite (HSAG) was Nano 27 from Asbury Graphite Mills, Inc. (Asbury, NJ, USA). According to the technical data sheet, the carbon content was not lower than $99 \%$ mass, the surface area was $250 \mathrm{~m}^{2} / \mathrm{g}$, and the chemical composition from elemental analysis (U.S. Standard Test Sieves) was carbon $99.82 \%$, ash $0.18 \%$, and moisture $0.97 \%$. The number of stacked layers was estimated, as already reported, [27-29] to be about 35 .

2,5-hexanedione (HD, $\mathrm{MW}=114.12 \mathrm{~g} / \mathrm{mol}$ ) was purchased from Sigma-Aldrich (purity $\geq 97 \%$ ), while 2-aminopropane-1,3-diol (serinol, purity $\geq 98 \%$ ) was kindly provided by Bracco. Acetone was purchased from Sigma-Aldrich (purity $\geq 97 \%$ ). All the chemicals were used without further purification.

For the preparation of elastomeric compounds, the following ingredients were used:

Silica ZEOSIL 1165MP Solvay: $\mathrm{SiO}_{2}: \mathrm{H}_{2} \mathrm{O}$ ratio $10: 1$, BET $\left(\mathrm{m}^{2} / \mathrm{g}\right)=140-180$, loss on drying $\left(2 \mathrm{~h} @ 105^{\circ} \mathrm{C}\right) \leq 8.0 \%$, and soluble salts $\left(\mathrm{as} \mathrm{Na}_{2} \mathrm{SO}_{4}\right) \leq 2.0 \%$.; a solution of styrenebutadiene synthetic rubber (S-SBR) from TRINSEO (commercial name: SPRINTAN ${ }^{\text {TM }}$ SLR4630), extended with 37.5 parts of TDAE oil, a styrene content of $25 \%$, and a Mooney viscosity of 55 (ML $\left.(1+4) 100{ }^{\circ} \mathrm{C}\right)$; Poly(1,4-cis-isoprene) from Hevea brasiliensis (NR) (STR/SMR/SIR 20, RSS3), from Von Bundit Co., Mueang, Phuket; Bis[3 -(triethoxysilyl)propyl] tetrasulfide (TESPT) purchased from Evonik; zinc oxide (ZnO), from Flexsys, Ann Arbor, Michigan; stearic acid, from Sogis, Sospiro (CR), Italy; (1,3-dimethyl butyl)-N'-Phenyl-p-phenylenediamine (6PPD) from Crompton, Mumbai, India; N-tert-butyl-2-benzothiazyl sulfonamide (TBBS), from Flexsys; and Sulphur, from Solfotecnica, Cotignola (RA), Italy.

\subsection{Synthesis of 2-(2,5-Dimethyl-1H-pyrrol-1-yl)propane-1,3-diol or Serinol Pyrrole (SP)}

The synthesis of SP has been already reported elsewhere [19]. For the sake of clarity, we also describe it here. A mixture of 2,5-hexanedione (HD, $12.15 \mathrm{~g}, 0.107 \mathrm{~mol}$ ) and 2aminopropane-1,3-diol (S, $9.96 \mathrm{~g}$; $0.107 \mathrm{~mol}$ ) was poured into a $100 \mathrm{~mL}$ round bottomed flask equipped with a magnetic stirrer and a condenser (single glass tube). The mixture was then stirred $(300 \mathrm{rpm})$ at $155^{\circ} \mathrm{C}$ for $3 \mathrm{~h}$. Then the condenser was removed, and the mixture was left stirring at $155^{\circ} \mathrm{C}$ for $30 \mathrm{~min}$. After, the reaction mixture was cooled to room temperature. In total, $15.51 \mathrm{~g}$ of pure dark amber viscous product was obtained: ${ }^{1} \mathrm{H}$ $\operatorname{NMR}\left(\mathrm{CDCl}_{3}, 400 \mathrm{MHz}\right) ; \delta(\mathrm{ppm})=2.27(\mathrm{~s}, 6 \mathrm{H}) ; 3.99(\mathrm{~m}, 4 \mathrm{H}) ; 4.42\left(\right.$ quintet, $\left.{ }^{1} \mathrm{H}\right) ; 5.79\left(\mathrm{~s},{ }^{2} \mathrm{H}\right)$. 13C NMR (DMSO-d6, 100 MHz); $\delta(\mathrm{ppm})=127.7 ; 105.9 ; 71.6 ; 61.2 ; 13.9$.

\subsection{Functionalization of High Surface Area Graphite with Serinol Pyrrole}

Ten grams of HSAG and $50 \mathrm{~mL}$ of acetone were introduced in a $250 \mathrm{~mL}$ roundbottomed flask and sonicated for 10 min using a $2 \mathrm{~L}$ ultrasonic bath $260 \mathrm{~W}$ (SONICA, SOLTEC Srl, Milan, Italy). A solution of $1 \mathrm{~g}$ of SP in $15 \mathrm{~mL}$ of acetone was added to the flask and another 10-min sonication was performed. Hence, the amount of pyrrole compound (PyC) was 10 parts per hundred parts of carbonaceous material (phc). The solvent was removed under reduced pressure using a rotary evaporator. The powder was then transferred to a two-neck $250 \mathrm{~mL}$ round bottomed flask equipped with a magnetic stirrer and an air condenser with sintered septum on the main neck, heated up to $180^{\circ} \mathrm{C}$ in an oil bath and left under stirring ( $300 \mathrm{rpm})$ for $2 \mathrm{~h}$ under air flux, introduced through the secondary neck of the flask. An acetone Soxhlet extraction was then performed on the obtained powder to remove the fraction of unreacted serinol pyrrole. The free-flowing powder was recovered and dried at RT for $24 \mathrm{~h}$. 


\subsection{Characterization of the HSAG-SP Adduct}

To determine the mass percentage of serinol pyrrole (SP) in the HSAG-SP adduct, TGA analysis was used. This characterization technique is commonly employed to verify the presence of organic compounds on the surface of carbonaceous fillers [30].

To determine the functionalization yield, TGA analysis was applied on samples of HSAG-SP adducts before and after acetone washing, and Equation (1) was used:

Functionalization Yield $(\%)=\frac{\text { SP mass } \% \text { in (HSAG-SP adduct) after acetone wash }}{\text { SP mass } \% \text { in (HSAG-SP adduct) before acetone wash }}$

To determine the amount of SP in the HSAG-SP adduct, expressed in parts per hundred parts of carbon (phc), the mass losses obtained from TGA analysis for the HSAG-SP adduct and for pristine HSAG were used, by applying Equation (2):

Phe of SP in HSAG-SP adduct

$\frac{\left.\text { (mass loss in T range: } 150{ }^{\circ} \mathrm{C}-700{ }^{\circ} \mathrm{C}\right)_{\text {washed HSAG-SP adduct }}-\left(\text { mass loss in T range: } 150{ }^{\circ} \mathrm{C}-700{ }^{\circ} \mathrm{C}\right) \text { washed pristine HSAG }}{\left[\left(\text { mass loss }>700{ }^{\circ} \mathrm{C}\right)_{\text {washed }} \text { HSAG-SP adduct }\right]}$

The TGA instrument used to perform thermogravimetric analyses was a Mettler TGA SDTA/851 (Mettler Toledo, Columbus, OH, USA). The standard method ISO9924-1 was followed. The method used for the analysis of adducts $(5-10 \mathrm{mg})$ consists of a heating ramp $\left(10{ }^{\circ} \mathrm{C} / \mathrm{min}\right)$ from 30 up to $300^{\circ} \mathrm{C}$, followed by a $10 \mathrm{~min}$ isotherm at $300{ }^{\circ} \mathrm{C}$, then another heating ramp $\left(20^{\circ} \mathrm{C} / \mathrm{min}\right)$ up to $550^{\circ} \mathrm{C}$, and another isotherm at $550^{\circ} \mathrm{C}(15 \mathrm{~min})$; this isotherm is followed by a final heating ramp $\left(10{ }^{\circ} \mathrm{C} / \mathrm{min}\right)$ up to $900{ }^{\circ} \mathrm{C}$, after which the temperature is kept constant until the end of the experiment. At $102.5 \mathrm{~min}$ from the beginning of the test, the gas in the chamber is switched from $\mathrm{N}_{2}$ to air. The whole experiment lasts $120 \mathrm{~min}$.

\subsection{Rubber Composites Preparation}

Compounds formulations, expressed in parts per hundred rubber (phr), are reported in Table 1. The amount of HSAG, when present, was kept constant.

Table 1. Recipes of S-SBR/NR-based composites with Silica, Silica/HSAG or Silica/HSAG-SP as reinforcing fillers ${ }^{\mathrm{a}, \mathrm{b}}$.

\begin{tabular}{cccccc}
\hline Composite & Neat Rubber & HSAG & Silica & Silica/HSAG & Silica/HSAG-SP \\
\hline S-SBR & 110 & 110 & 110 & 110 & 110 \\
NR & 20 & 20 & 20 & 20 & 20 \\
Silica & $/$ & $/$ & 50 & 42.5 & 42.5 \\
TESPT & $/$ & $/$ & 4 & 4 & 4 \\
HSAG & $/$ & 8.2 & $/$ & 8.2 & $/$ \\
HSAG-SP & $/$ & $/$ & $/$ & $/$ & $8.9^{\mathrm{c}}$ \\
\hline
\end{tabular}

a Amount of ingredients in phr. ${ }^{\mathrm{b}}$ Other ingredients: Stearic Acid 2, Zinc oxide 2.5, 6PPD 2, TBBS 1.8, sulphur 2.

c $8.2 \mathrm{phr}$ of HSAG and $0.7 \mathrm{phr}$ of Serinol Pyrrole (SP).

For each composite, a master batch made by the elastomer, fillers (if present), silane (when necessary), and stearic acid was prepared using a HAAKE ${ }^{\circledR}$ internal mixer (Haake Rheomix $600^{\circledR}$ ). The other ingredients (the vulcanizers) were then added in a further step in a Brabender ${ }^{\circledR}$ internal mixer (Brabender ${ }^{\circledR}$ PL-2000 Plasti-Corder Torque Rheometer, Brabender GmbH \& Co. KG, Duisburg, Germany). Mixing time was kept constant for all the composites.

For the S-SBR/NR-based master batch, S-SBR and NR were fed into a HAAKE ${ }^{\circledR}$ internal mixer and masticated for $30 \mathrm{~s}$ at $100{ }^{\circ} \mathrm{C}$ and $85 \mathrm{rpm}$. Then, when necessary, Silica and TESPT were added, and another $1 \mathrm{~min}$ and $30 \mathrm{~s}$ of mastication was carried out. Next, stearic acid and HSAG or HSAG-SP (when present) were added, followed by another 1 min and $30 \mathrm{~s}$ of mastication before compound discharge.

All master batches were completed in a Brabender ${ }^{\circledR}$ internal mixer. The master batch was fed into a Brabender ${ }^{\circledR}$ internal mixer at $50{ }^{\circ} \mathrm{C}$, with $88 \%$ as the fill factor. After 1 min of mixing, zinc oxide and 6PPD were added, 2 min of mastication followed. Finally, TBBS and sulphur were added. After 2 min of mixing, the final compound was discharged. 
Composites were finally further homogenized by passing them 5 times through a two-roll mill operating at $50{ }^{\circ} \mathrm{C}$, with the front roll rotating at $30 \mathrm{rpm}$, the back roll rotating at $38 \mathrm{rpm}$, and $1 \mathrm{~cm}$ as the nip between the rolls.

\subsection{Preparation of Specimens for Mechanical Characterization}

The elastomer composite was processed in a two-roll mill, as described above. Then two different vulcanizing procedures were followed to prepare the desired test pieces.

Quasi static tensile tests. The elastomeric compound coming out of the two-roll mill was vulcanized in a vulcanizing press to produce a $1 \mathrm{~mm}$ thick vulcanized plate. ISO 37 dumbbell-shaped test specimens with a test length of $10 \pm 0.5 \mathrm{~mm}$ and a width of $4 \pm 0.2 \mathrm{~mm}$ (type 3 ) were punched from the vulcanized plate.

Dynamic-mechanical analyses in compression. After processing the rubber compound in a two-roll mill, the material was rolled up to obtain a long cylinder. The rolled-up cylinder was then cut into smaller cylinders and vulcanized to produce cylindrical test pieces with length $=25 \mathrm{~mm}$ and diameter $=12 \mathrm{~mm}$.

Dynamic-mechanical analyses in shear configuration to evaluate mechanical anisotropy. The elastomeric compound coming out of the two-roll mill was vulcanized in a vulcanizing press to produce a $2 \mathrm{~mm}$ thick vulcanized plate.

\subsection{Crosslinking}

A rubber process analyzer (RPA, Alpha Technologies, Hudson, OH, USA) was employed to monitor the crosslinking reaction carried out at $170{ }^{\circ} \mathrm{C}$ for $20 \mathrm{~min}$. Five grams of crude rubber compound were introduced into the rheometer. Before the crosslinking step, a strain sweep was performed at strain amplitude in the $0.1-25 \%$ range, then the sample was kept at $50{ }^{\circ} \mathrm{C}$ for ten minutes and subjected to another strain sweep at $50{ }^{\circ} \mathrm{C}$. Subsequently vulcanization at $170{ }^{\circ} \mathrm{C}$ was performed and the torque versus time was measured, determining the minimum achievable torque $\left(\mathrm{M}_{\mathrm{L}}\right)$, the maximum achievable torque $\left(\mathrm{M}_{\mathrm{H}}\right)$, the time needed to have a torque equal to $\mathrm{M}_{\mathrm{L}}+1 \mathrm{dNm}\left(\mathrm{t}_{\mathrm{S} 1}\right)$, and the time needed to reach $90 \%$ of the maximum torque $\left(t_{90}\right)$. The oscillation angle was $6.28^{\circ}$, and the frequency was $1.7 \mathrm{~Hz}$.

\subsection{Strain Sweep Tests}

Shear dynamic-mechanical properties were measured using a rubber process analyzer (RPA), in particular, a Monsanto Oscillating disk rheometer (RPA2000) with a sealed test cavity with biconical dies having a volume of $4.5 \mathrm{~cm}^{3}$ and a diameter of $4 \mathrm{~cm}$. A strain sweep was performed on the crude sample at strain amplitude in the $0.1-25 \%$ range, then the sample was kept at $50{ }^{\circ} \mathrm{C}$ for ten minutes and subjected to another strain sweep at $50{ }^{\circ} \mathrm{C}$ before being vulcanized as described in paragraph 2.7. After $20 \mathrm{~min}$ at $50{ }^{\circ} \mathrm{C}$, shear dynamic-mechanical properties were measured, applying a $0.1-25 \%$ strain sweep at a frequency of $1 \mathrm{~Hz}$. The measured properties were shear storage and loss moduli $\left(G^{\prime}, G^{\prime \prime}\right)$.

\subsection{Quasistatic Tensile Tests}

The quasistatic tensile experiments were conducted on dumbbell-shaped test specimens, prepared as described above. The tests were conducted with a Zwick universal testing machine (Zwick Roell Z001, Test expert, Ulm, Germany) and an optical extensometer. Each material grade was characterized implementing three specimens to ensure reproducibility. Stresses at 50,100 , and $300 \%$ of elongation $\left(\sigma_{50}, \sigma_{100}, \sigma_{300}\right.$ respectively) were determined, as well as stress at break $\left(\sigma_{\mathrm{B}}\right)$, elongation at break $\left(\varepsilon_{\mathrm{B}}\right)$, and energy at break.

\subsection{Dynamic-Mechanical Analyses in Compression}

Cylindrical vulcanized specimens were prepared as described above. An Instron dynamic device in the traction-compression mode was employed to perform dynamicmechanical measurements, keeping the materials at the following temperatures $(10,23$, or $\left.70{ }^{\circ} \mathrm{C}\right)$. 
An axial compressive pre-strain of $25 \%$ was performed on the specimen followed by a sinusoidal axial strain sweep with an amplitude of $\pm 3.5 \%$ with respect to the applied pre-strain, with a $100 \mathrm{~Hz}$ frequency.

Dynamic-mechanical storage modulus ( $\left.E^{\prime}\right)$ and loss factor (tan delta) were registered.

\subsection{High Pressure Capillary Viscosimeter (HKV) Measurements}

Tests were conducted using a high pressure capillary viscosimeter, type "RheoVulkameter 78.90" (Göttfert Werkstoff-Prüfmaschinen GmbH). Crude compound material was forced to flow into a $20 \mathrm{~mm}$ capillary with a $2 \mathrm{~mm}$ diameter at a pressure of $130 \mathrm{bar}$. The mold temperature was set at $100{ }^{\circ} \mathrm{C}$. A preheating step at $100{ }^{\circ} \mathrm{C}$ of $180 \mathrm{~s}$ and an injection of $60 \mathrm{~s}$ were carried out.

\subsection{Mooney Viscosity Measurements}

Mooney viscosity was determined with a Mooney MV 2000 E Viscometer from Alpha Technologies, by applying the experimental procedure reported in ASTM D1646. Tests were run at $100{ }^{\circ} \mathrm{C}$, using a rotor with a $38.10 \mathrm{~mm}$ diameter rotating at $0.209 \mathrm{rad} / \mathrm{s}$. Rubber samples were preheated for $1 \mathrm{~min}$ at $100{ }^{\circ} \mathrm{C}$, and the rotor was allowed to rotate for $4 \mathrm{~min}$ before measuring the viscosity value, represented by the torque measured in Mooney Units (MU).

\subsection{Dynamic-Mechanical Analysis (DMA) in Shear Mode for Anisotropy Analysis}

Dynamic-mechanical tests were carried out by means of a shear-sandwich configuration (see Figure 1a) using a Q800 dynamic-mechanical analyzer (TA Instruments). The test procedure is described in [31,32], and is summarized here. Rectangular specimens with nominal dimensions of $2 \times 2 \times 6 \mathrm{~mm}^{3}$ were obtained by cutting $2 \mathrm{~mm}$ thick plates of vulcanized rubber (see Figure $1 \mathrm{~b}$ ). Tests were carried out at room temperature, $1 \mathrm{~Hz}$, in strain sweep mode. During each test, first, a conditioning strain sweep from $0.02 \%$ to $25 \%$ of shear amplitude was carried out, followed by a rest time of $10 \mathrm{~min}$ to allow material recovery, and a final strain sweep $(0.02-25 \%$ of shear amplitude) was carried out. $G^{\prime}$ and $G^{\prime \prime}$ values of the second sweep are reported and analyzed in this work. In order to investigate the mechanical behavior along different directions, the tests were carried out according to two test configurations, labelled "through-thickness" (TT) and "in-plane" (IP), and schematically represented in Figure 1c. In the TT configuration, strain was applied to the specimen on the surfaces corresponding to the outer surfaces of the original rubber plate (grey broken figure in Figure 1c), and deformation occurred through the sample thickness. In the IP configuration, strains were applied to the surfaces obtained by cutting the specimens from the original rubber plate, and deformation occurred in planes parallel to the sample surface. At least three repetitions were carried out for each material and test configuration. 

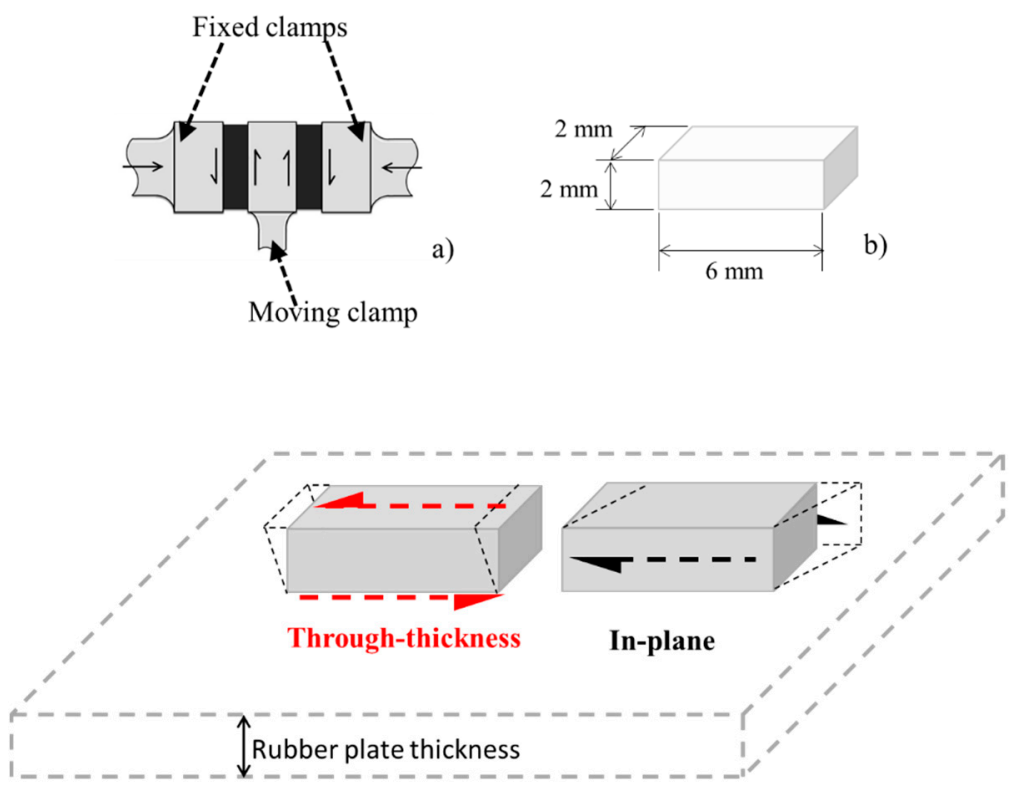

c)

Figure 1. (a) Sketch of shear sandwich configuration adopted in dynamic-mechanical tests; clamps are grey, rubber specimens are black colored; (b) geometry and nominal dimensions of a rubber sample for DMA tests; (c) loading configurations of DMA tests: rubber plate (grey broken line), specimens (full grey parallelepipeds), shear strains applied (arrows) and deformed shapes (black broken lines) are displayed.

\subsection{Morphological Analysis by Means of TEM}

Filler dispersion on a small scale in rubber was investigated via transmission electron microscopy (TEM, LIBRA ${ }^{\circledR}$ 120, Zeiss, Oberkochen (Baden-Württemberg), Germany), acceleration voltage of $120 \mathrm{kV}$. Samples were prepared by performing ultra-thin cuts of approximately $100 \mathrm{~nm}$ thickness on cured compound samples under liquid nitrogen, using a diamond cutter mounted on a Leica Ultramicrotome UC6, equipped with a stereo microscope MZ6 and a FC6 cutting system.

\section{Results and Discussion}

3.1. Functionalization of HSAG with Serinol Pyrrole via the Pyrrole Methodology

Functionalization of HSAG was performed with SP, applying a method already described in previous publications [26], also named "pyrrole methodology", which is also shown, for the sake of clarity, in Figure 2 and is described in detail in the Section 2.
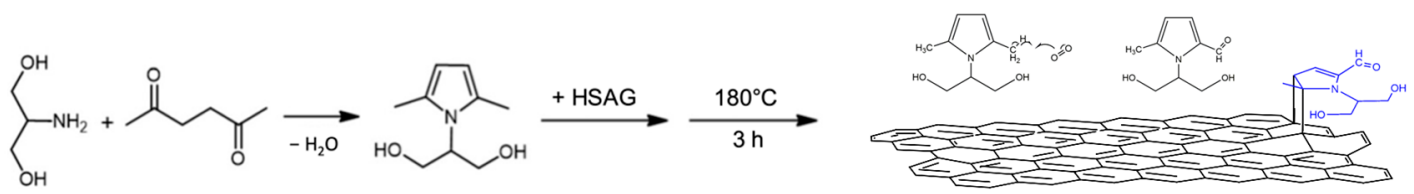

Figure 2. Scheme of the domino reaction for the functionalization of HSAG with serinol pyrrole [26].

In brief, SP was obtained by mixing and heating serinol and the diketone. Functionalization was then performed by simply adsorbing the pyrrole compound on the surface of the $\mathrm{sp}^{2}$ carbon allotrope and then heating at $180^{\circ} \mathrm{C}$ under air flux for $2 \mathrm{~h}$. In this work, the functionalization reaction was performed by using a theoretical HSAG/SP mass ratio of 10:1. This functionalization method, from the synthesis of SP to the preparation of the HSAG/SP adduct, was characterized by a high atom economy, the only co-product being water. To check the efficiency of the functionalization reaction, thermogravimetric analysis (TGA) was employed, as described in the Section 2. Organic mass losses of the HSAG-SP 
adduct before and after an exhaustive acetone washing were compared. Curves are shown in Figure 3. Mass losses are in Table 2.

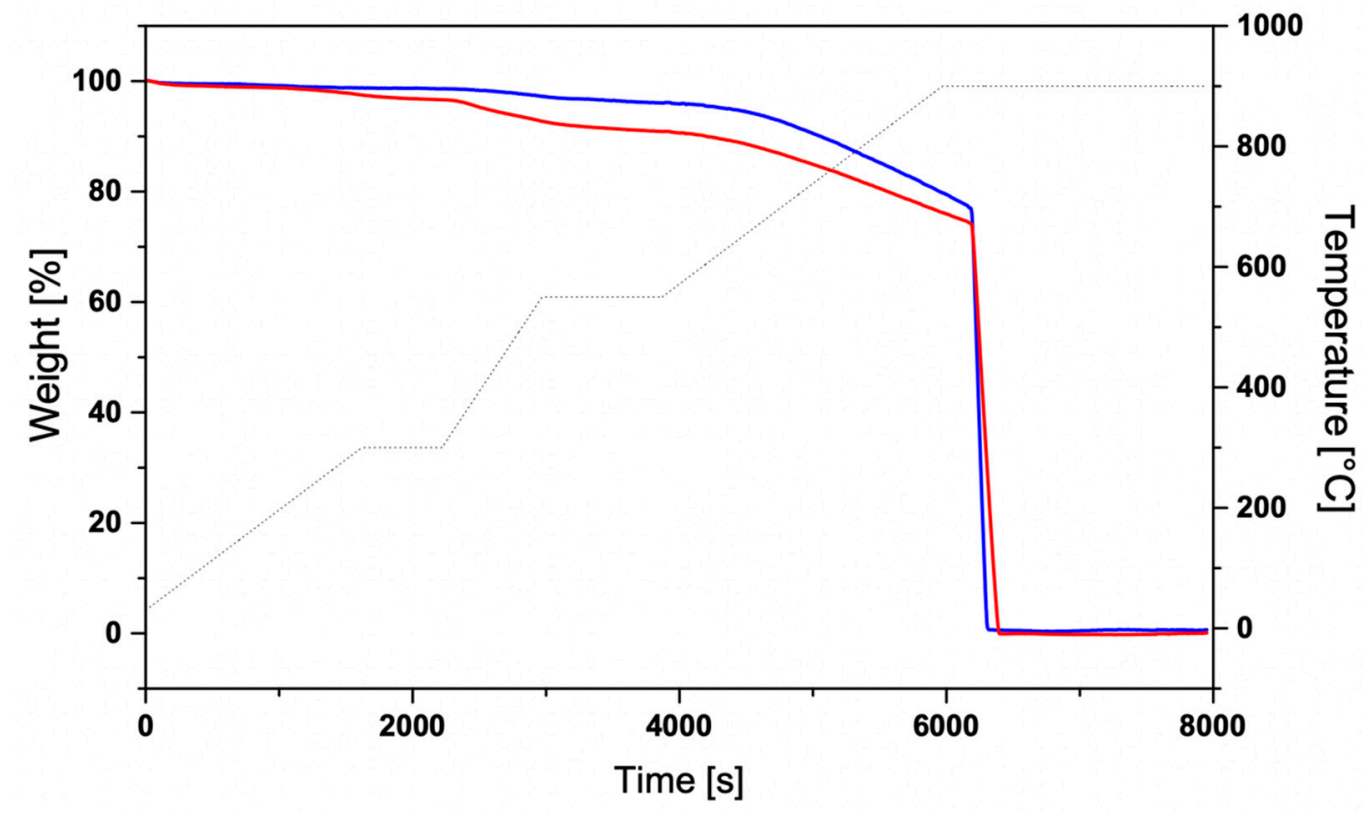

Figure 3. Thermogravimetric analysis of pristine HSAG (blue line), and HSAG-SP after acetone extraction (red line).

Table 2. Mass losses for pristine HSAG and HSAG-SP adduct, determined via TGA.

\begin{tabular}{|c|c|c|c|c|c|}
\hline \multirow[b]{2}{*}{$\begin{array}{c}\text { Temperature } \\
\text { Range }\end{array}$} & & \multicolumn{4}{|c|}{ Mass Loss (\%) } \\
\hline & & $\mathrm{T}<150^{\circ} \mathrm{C}$ & $150{ }^{\circ} \mathrm{C}<\mathrm{T}<400^{\circ} \mathrm{C}$ & $400{ }^{\circ} \mathrm{C}<\mathrm{T}<700^{\circ} \mathrm{C}$ & $\mathrm{T}>700^{\circ} \mathrm{C}$ \\
\hline \multirow[t]{2}{*}{ HSAG } & (a) & 0.4 & 1.5 & 3.5 & 91.1 \\
\hline & (c) & 0.0 & 0.1 & 0.4 & 99.5 \\
\hline \multirow[t]{2}{*}{ HSAG-SP } & (b) & 0.3 & 5.7 & 3 & 91.6 \\
\hline & (c) & 0.4 & 5.4 & 3.1 & 91.1 \\
\hline
\end{tabular}

(a) pristine, (b) after the functionalization reaction, and (c) after washing with acetone (see Section 2).

The mass losses detected below $150^{\circ} \mathrm{C}$, for both HSAG and HSAG-SP, were attributed to absorbed water or solvent. Mass losses detected between $150{ }^{\circ} \mathrm{C}$ and $700{ }^{\circ} \mathrm{C}$ for pristine HSAG were due to alkenylic defects present on the surface of the carbonaceous filler. Mass losses in the range $150-700{ }^{\circ} \mathrm{C}$ for the HSAG-SP adduct were attributed to the presence of SP [20]. As shown by the data in Table 2, organic mass losses remained appreciable after an exhaustive acetone extraction of the HSAG-SP adduct, thus giving evidence for the formation of a stable adduct. The functionalization yield was estimated according to Equation (1) reported in the Section 2. A high functionalization yield was achieved: $97.7 \%$. It can be thus commented that the functionalization of HSAG with SP occurred with high atom efficiency [33]. The amount of SP in the adduct was calculated to be 8.7 parts per hundred parts of carbon. In the laboratory procedure, a solvent (acetone) was used to promote the dispersion of the reagents, but different methods, such as a spray dry, can be applied at a pre-industrial scale, thus avoiding the use (and the need of recycling) organic substances.

The infrared characterization of the HSAG-SP adduct has been discussed elsewhere [23]. The expected spectral features of serinol pyrrole were identified for the HSAG-SP sample used in this work. 


\subsection{Rubber Composites Preparation and Characterization}

A poly(styrene-co-butadiene) rubber from anionic solution polymerization (S-SBR) was used for the preparation of the rubber compounds alongside a minor portion of natural rubber (NR), with silica as the only or the main filler. Compounding was performed via melt blending, using the formulations reported in Table 1 above. A silica volume equal to $15 \%(7.5 \mathrm{phr})$ was replaced with HSAG and HSAG-SP at equal volume. The organic modifier in HSAG-SP was considered as an extra ingredient. The same amount of coupling agent was used in all the formulations, in order to have the same type and amount of sulphur in all the composites. Two more composites were prepared, one without filler(s) and one with HSAG as the only filler.

\subsubsection{Curing}

Crosslinking was performed with a classical sulphur-based system and the results from the rheometric tests for the composites with silica and the hybrid silica/HSAG filler system, collected as reported in the Section 2, are shown in Table 3.

Table 3. Curing data of rubber compounds of Table 1.

\begin{tabular}{cccc}
\hline Composite & Silica & Silica/HSAG & Silica/HSAG-SP \\
\hline $\mathrm{M}_{\mathrm{L}}(\mathrm{dNm})$ & 3.2 & 2.8 & 2.6 \\
$\mathrm{M}_{\mathrm{H}}(\mathrm{dNm})$ & 15.3 & 13.8 & 13.6 \\
$\mathrm{M}_{\mathrm{H}}-\mathrm{M}_{\mathrm{L}}(\mathrm{dNm})$ & 12.1 & 11.1 & 10.9 \\
$\mathrm{t}_{90}(\mathrm{~min})$ & 10.9 & 10.6 & 10.7 \\
$\mathrm{t}_{\mathrm{S} 1}(\mathrm{dNm})$ & 3.2 & 3.2 & 3.4 \\
$\left(\mathrm{M}_{\mathrm{H}}-\mathrm{M}_{\mathrm{L}}\right) /\left(\mathrm{t}_{90}-\mathrm{t}_{\mathrm{s} 1}\right)$ & 1.6 & 1.5 & 1.5 \\
\hline
\end{tabular}

The replacement (for a same volume amount) of $15 \%$ of silica with pristine or functionalized HSAG led to a reduction in the $\mathrm{M}_{\mathrm{L}}$ and $\mathrm{M}_{\mathrm{H}}$ values. In particular, the lowest $\mathrm{M}_{\mathrm{L}}$ value was achieved with HSAG-SP. $\mathrm{M}_{\mathrm{L}}$ is usually correlated with the composite viscosity. It can be commented that HSAG-SP promotes the reduction in the viscosity of silica-based composites. Small differences were detected, for the three composites of Table 3, among the values of $t_{s 1}, t_{90}$ and $\left(M_{H}-M_{L}\right) /\left(t_{90}-t_{s 1}\right)$, parameters that indicate the induction and optimum vulcanization times and the vulcanization rate, respectively. Hence, HSAG does not appreciably affect the curing kinetics. The presence of a slight marching modulus effect was observed, which was not appreciably affected by the addition of HSAG.

\subsubsection{Dynamic-Mechanical Shear Properties}

Dynamic-mechanical properties were determined for the composites with silica and the hybrid silica/HSAG filler system, by applying the sinusoidal stress in the shear mode, performing strain sweep experiments as described in the Materials and Method Section 2.8 using a Rubber Process Analyzer (RPA). Storage modulus ( $\left.\mathrm{G}^{\prime}\right)$ at minimum and maximum strain, maximum loss modulus $\left(G^{\prime \prime}\right)$, and maximum Tan Delta $\left(G^{\prime \prime}{ }_{\max } / G^{\prime}{ }_{\max }\right)$ were obtained for the rubber composites incorporating Silica, Silica/HSAG, and Silica/HSAG-SP. Results are reported in Table 4 and Figure 4.

Table 4. Storage modulus $G^{\prime}$ at minimum $(0.1 \%)$ shear strain, $\Delta \mathrm{G}^{\prime}\left(\mathrm{G}_{0.1 \%}^{\prime}-\mathrm{G}_{25}^{\prime}\right.$ ), maximum loss modulus $G^{\prime \prime}$ max , and maximum tan $\operatorname{delta}_{\max }\left(\mathrm{G}^{\prime \prime}{ }_{\max } / \mathrm{G}^{\prime}{ }_{\max }\right)$ from strain sweep tests of the rubber compounds of Table 1 .

\begin{tabular}{cccc}
\hline Composite & Silica & Silica/HSAG & Silica/HSAG-SP \\
\hline $\mathrm{G}^{\prime}{ }_{0.1 \%}$ & 1.61 & 1.42 & 1.40 \\
$\Delta \mathrm{G}^{\prime}=\left(\mathrm{G}_{0.1 \%}^{\prime}-\mathrm{G}^{\prime}{ }_{25 \%}\right)$ & 0.86 & 0.72 & 0.72 \\
$\mathrm{G}^{\prime \prime} \max$ & 0.14 & 0.12 & 0.12 \\
$\tan$ delta $_{\max }$ & 0.15 & 0.14 & 0.13 \\
\hline
\end{tabular}




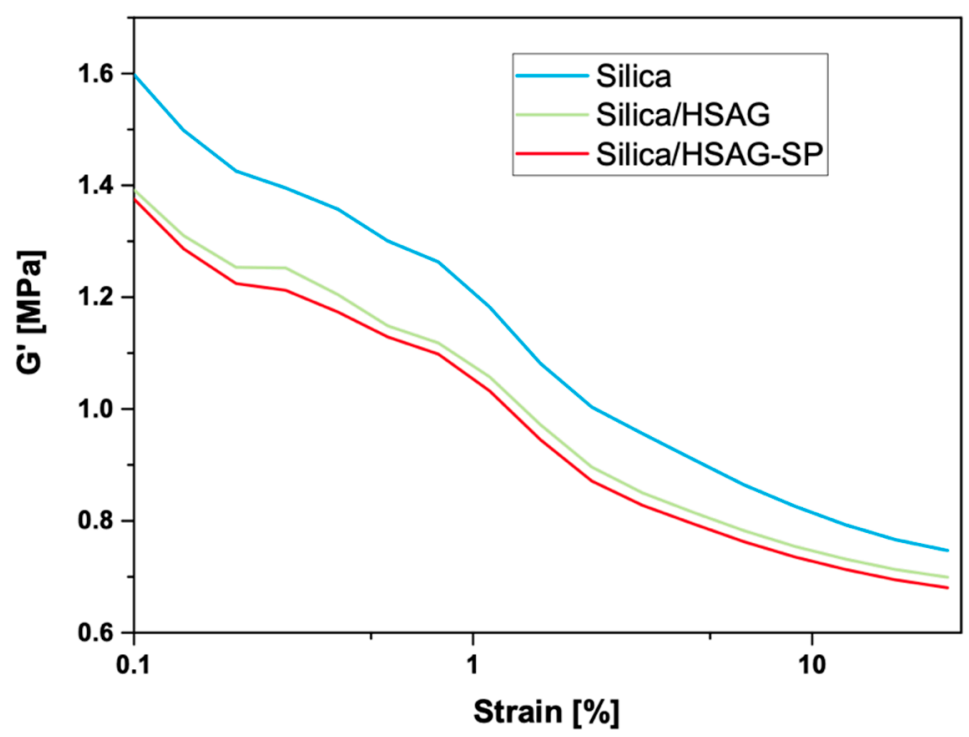

(a)

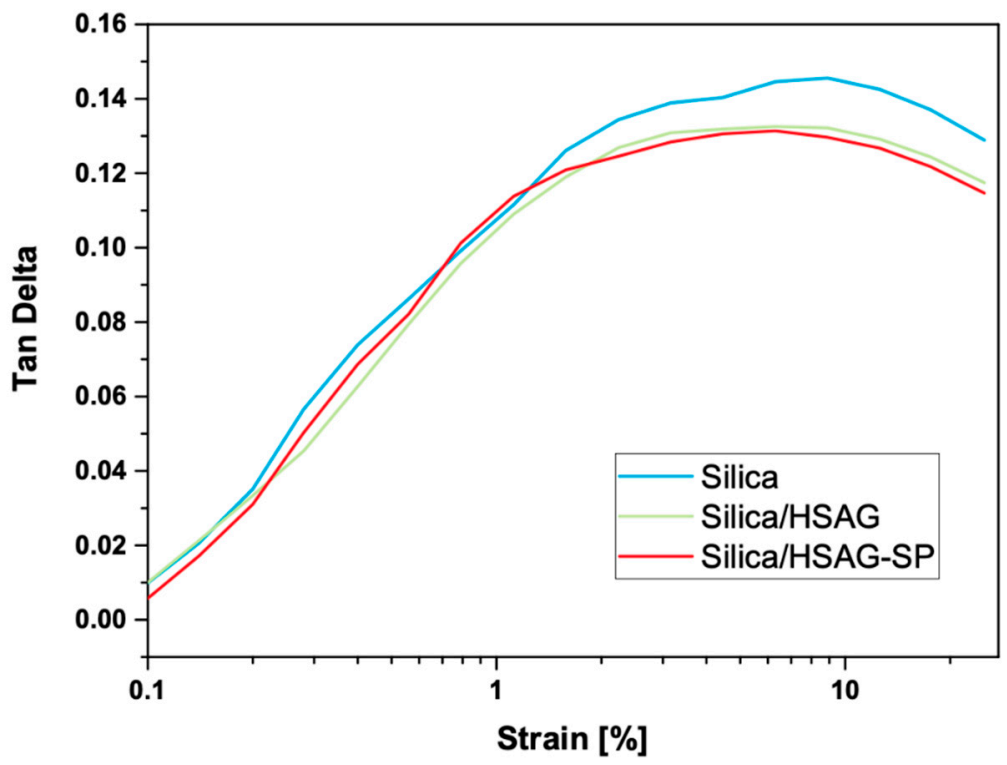

(b)

Figure 4. (a) storage modulus curves $\left(\mathrm{G}^{\prime}\right)$ and (b) tan delta curves obtained from dynamic-mechanical analyses in shear for the reference silica composite and composites with a 15\% silica replacement (at constant volume) with either HSAG or HSAG-SP.

The use of HSAG in place of silica led to an appreciable reduction in $\mathrm{G}^{\prime} \gamma \min , \Delta \mathrm{G}^{\prime}$, and $\mathrm{G}^{\prime \prime}$ max., to the same extent. A slightly lower value of tan delta was obtained for the composite with HSAG-SP. These findings can be reasonably explained with the reduction in the filler networking phenomenon.

\subsubsection{Dynamic-Mechanical Axial Properties}

Dynamic-mechanical properties were also determined for the composites with silica and the hybrid silica/HSAG filler system in the axial mode, by applying the sinusoidal stress in compression, as described in the Section 2. The dependence on the temperature of the storage modulus $\left(E^{\prime}\right)$ and of the loss factor Tan Delta $\left(E^{\prime \prime} / E^{\prime}\right)$ are shown in Figure $5 a, b$, respectively. 


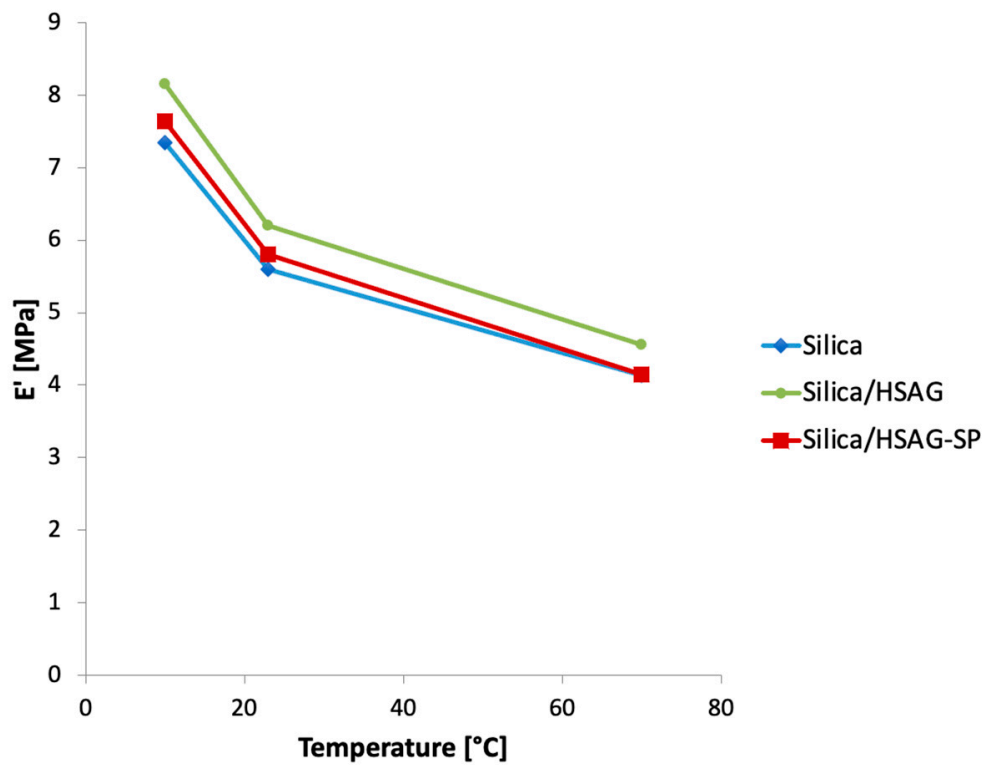

(a)

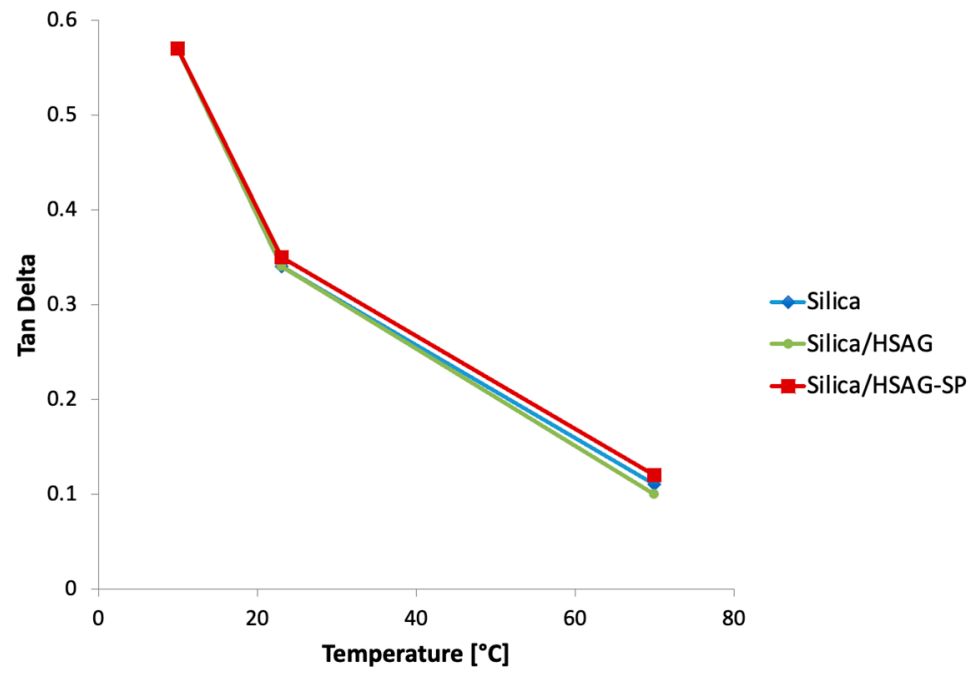

(b)

Figure 5. (a) storage modulus curves $\left(E^{\prime}\right)$ and (b) tan delta curves obtained from dynamic-mechanical analyses in compression for the reference silica composite and composites with a $15 \%$ silica replacement (at constant volume) with either HSAG or HSAG-SP.

The replacement of silica with HSAG-SP did not appreciably modify the dynamic properties of the composite, whereas a higher dynamic stiffness was obtained with pristine HSAG. The addition of HSAG or HSAG-SP did not lead to relevant differences in Tan Delta values.

\subsubsection{Quasistatic Tensile Tests}

The tensile properties of vulcanized rubber composites incorporating Silica, Silica/HSAG and Silica/HSAG-SP were measured by performing quasistatic tensile tests as described in the Section 2 . The values with the corresponding standard deviations are in Table 5 and the curves are shown in Figure 6. Remarkable differences were not observed for the stresses at 50\%, 100\%, and 300\% elongations. The replacement of silica with HSAG led to a relevant worsening of the ultimate properties, as documented by the 
reduction in stress and elongation at break, whereas similar values were obtained for the composite with HSAG-SP. Typically, ultimate properties are taken as an indication of filler dispersion, since the presence of local aggregates can be detrimental. Taking this into account, the comparison of Silica/HSAG and Silica/HSAG-SP suggests an improvement of filler dispersion promoted by SP in the hybrid filler systems.

Table 5. Stress at 50\% $\left(\sigma_{50}\right), 100 \%\left(\sigma_{100}\right)$, and 300\% $\left(\sigma_{300}\right)$ strain, stress at break, and strain at break of vulcanized rubber composites of Table 1.

\begin{tabular}{cccc}
\hline Composite & Silica & Silica/HSAG & Silica/HSAG-SP \\
\hline$\sigma_{50}(\mathrm{MPa})$ & $0.98 \pm 0.04$ & $1.2 \pm 0.03$ & $1.03 \pm 0.03$ \\
$\sigma_{100}(\mathrm{MPa})$ & $1.7 \pm 0.09$ & $2.1 \pm 0.06$ & $1.8 \pm 0.08$ \\
$\sigma_{300}(\mathrm{MPa})$ & $8.2 \pm 0.3$ & $8.8 \pm 0.12$ & $8 \pm 0.27$ \\
$\sigma_{\mathrm{B}}(\mathrm{MPa})$ & $19.3 \pm 1$ & $11.7 \pm 4.3$ & $18.4 \pm 0.16$ \\
$\varepsilon_{\mathrm{B}}(\%)$ & $512.4 \pm 7.9$ & $393.6 \pm 84$ & $534.1 \pm 11.7$ \\
\hline
\end{tabular}

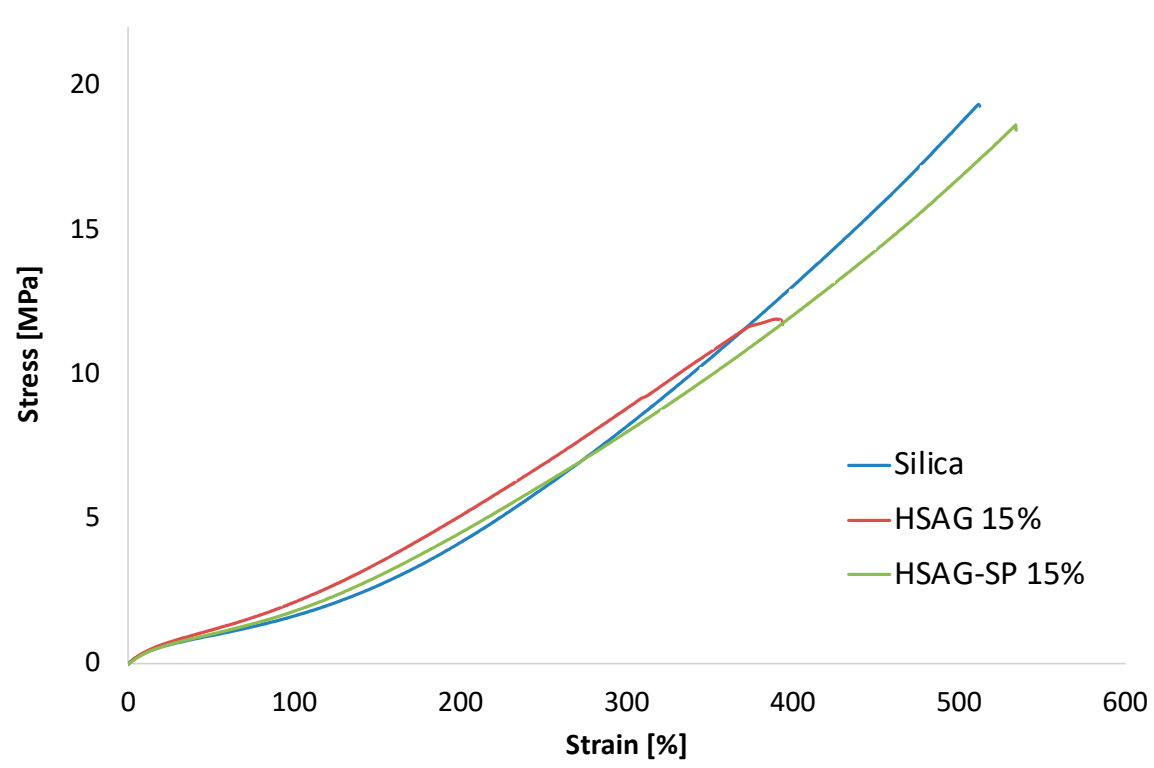

Figure 6. Stress-strain curves of vulcanized rubber-based composites containing either Silica, Silica/HSAG, or Silica/HSAG-SP as fillers.

\subsubsection{High Pressure Capillary Viscosimeter (HKV) Tests}

As mentioned in the introduction, the rheological properties are a drawback of silicabased composites. Investigation into the rheological properties of the composites in Table 1 was completed by measuring the Mooney viscosity and by performing the HKV-tests, by applying the methods described in the Section 2. Mooney data are in Table 6.

Table 6. Mooney viscosity of vulcanized composites of Table 1 . The Mooney Viscosity, registered as a torque in Mooney Units (MU), was measured at $100^{\circ} \mathrm{C}$ after a preheat time of $1 \mathrm{~min}$ and a test running time of $4 \min \left(\mathrm{M}_{\mathrm{L}\left(100^{\circ} \mathrm{C}, 1+4\right)}\right)$.

\begin{tabular}{cccc}
\hline Composite & Silica & Silica/HSAG & Silica/HSAG-SP \\
\hline $\mathrm{M}_{\mathrm{L}\left(100^{\circ} \mathrm{C}, 1+4\right)}$ & 73.8 & 71.1 & 68.7 \\
\hline
\end{tabular}

The replacement of silica with HSAG led to a slight lowering of the composite Mooney viscosity, whereas the reduction appears to be appreciable for the composite with HSAG-SP.

The HKV tests were performed in order to study the processability of rubber compounds in the shear rate range typically experienced during the processing. The curves obtained from the HKV -tests are in Figure 7. They show the amount of compound flowing 
through the capillary of the HKV versus time. Curves were taken immediately after the preparation of the composites and after 7 days of aging at room temperature.

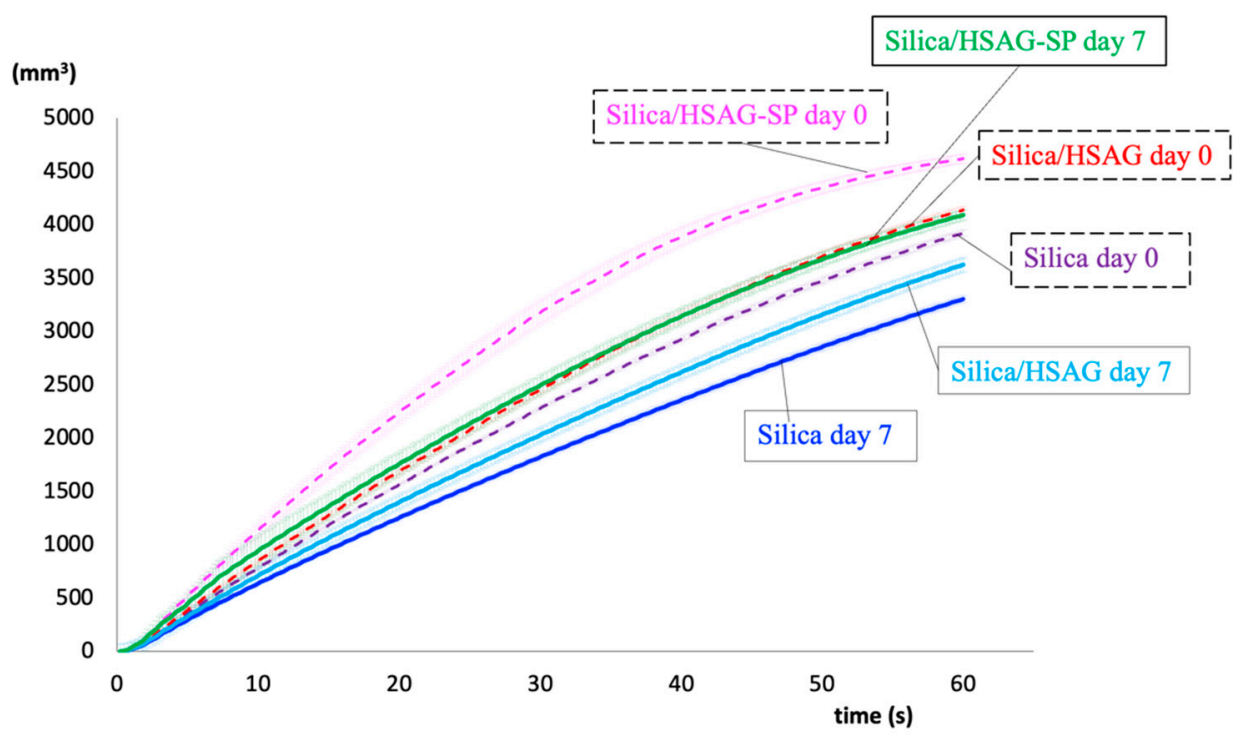

Figure 7. HKV curves of the rubber composites incorporating silica, silica/HSAG, and silica/HSAGSP measured at day zero (dashed line) and after a 7-day aging (continuous line). The graph shows the amount of silica (in $\mathrm{mm}^{3}$ ) released by the instrument vs. time.

Tests performed on unaged samples reveal the appreciably higher flowability of the composite with HSAG-SP, whereas the amount of released silica in the presence of pristine HSAG appears to be only slightly higher. After 7 days storage, the improvement of composite flowability, due to the presence of HSAG-SP, appears to be more pronounced. It is worth observing that the flowability of the HSAG-SP filled composite, after 7 days storage, and of the not stored silica-based composite, are the same. This indicates a high polymer-filler interaction. Moreover, after 7 days storage, the effect of pristine HSAG appears to be lower, which means higher viscosity, due to reagglomeration of the filler.

\subsubsection{Anisotropic Properties}

In order to investigate the anisotropic mechanical behavior of the systems, DMA tests were carried out on specimens taken from plates in shear-sandwich configuration. This approach was selected instead of using an RPA machine for two reasons. Firstly, the production process of the plate (two-roll mill followed by compression molding) favors a layered structuring of lamellar nanographite, as already investigated by some of the authors [31]. Secondly, the use of parallelepiped-shaped specimens enables modifying the loading configuration from a through-thickness (TT) to an in-plane (IP) application of the shear load (see Figure 1) without altering the specimen geometry.

Table 7 shows the data of storage modulus at minimum $(0.02 \%)$ and at maximum $(21 \%)$ shear strain amplitude, both in IP and TT configuration (as specified in the subscripts):

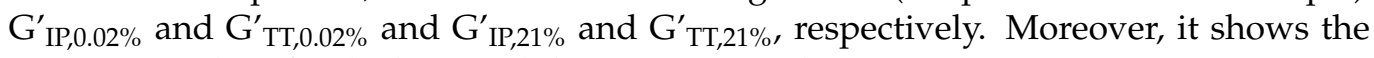
maximum values for the loss modulus: $G^{\prime \prime}{ }_{\text {max,IP }}$ and $G^{\prime \prime}{ }_{\text {max,TT }}$.

For each of these parameters, the effect of anisotropy was evaluated in terms of a conveniently defined anisotropy index, calculated as the ratio of the value in IP over the value in TT configuration: anisotropy index equal to 1 indicates an isotropic behavior for the material, whereas a value higher than 1 means that the material has an anisotropic behavior. In the latter case, it was observed [31] that HSAG, in a rubber composite prepared with the same procedure adopted in the present work, led to an orthotropic and transversally isotropic behavior. All data are in Table 7. 
Table 7. Data of storage modulus $\mathrm{G}^{\prime}$ at minimum $(0.021 \%)$ shear strain amplitude, at maximum shear strain amplitude (21\%), and of maximum value of loss modulus ( $\mathrm{G}^{\prime \prime}$ max), both in IP and TT configuration, and anisotropy index of rubber composites of Table 1. Average values with standard deviations are reported.

\begin{tabular}{|c|c|c|c|c|c|}
\hline Composite & Neat Rubber & HSAG & Silica & Silica/HSAG & Silica/HSAG-SP \\
\hline $\mathrm{G}_{\mathrm{IP}, 0.02 \%}^{\prime}$ & $0.344 \pm 0.018$ & $0.42 \pm 0.03$ & $1.892 \pm 0.006$ & $2.24 \pm 0.03$ & $2.09 \pm 0.09$ \\
\hline $\mathrm{G}_{\mathrm{TT}, 0.02 \%}^{\prime}$ & $0.343 \pm 0.007$ & $0.37 \pm 0.03$ & $1.7 \pm 0.1$ & $1.85 \pm 0.03$ & $1.78 \pm 0.06$ \\
\hline $\mathrm{G}_{\mathrm{IP}, 0.02 \%}^{\prime} / \mathrm{G}^{\prime} \mathrm{TT}, 0.02 \%$ & $1.00 \pm 0.06$ & $1.11 \pm 0.12$ & $1.11 \pm 0.08$ & $1.21 \pm 0.03$ & $1.18 \pm 0.06$ \\
\hline $\mathrm{G}_{\mathrm{IP}, 21 \%}^{\prime}$ & $0.321 \pm 0.017$ & $0.35 \pm 0.06$ & $0.87 \pm 0.06$ & $1.11 \pm 0.03$ & $1.10 \pm 0.04$ \\
\hline $\mathrm{G}_{\mathrm{TT}, 21 \%}^{\prime}$ & $0.325 \pm 0.010$ & $0.35 \pm 0.03$ & $0.86 \pm 0.05$ & $0.986 \pm 0.008$ & $0.96 \pm 0.08$ \\
\hline $\mathrm{G}_{\mathrm{IP}, 21 \%}^{\prime} / \mathrm{G}_{\mathrm{TT}, 21 \%}^{\prime}$ & $0.99 \pm 0.06$ & $1.01 \pm 0.17$ & $1.01 \pm 0.09$ & $1.12 \pm 0.03$ & $1.14 \pm 0.06$ \\
\hline $\mathrm{G}_{\text {max,IP }}^{\prime \prime}$ & * & * & $0.206 \pm 0.006$ & $0.268 \pm 0.006$ & $0.258 \pm 0.013$ \\
\hline $\mathrm{G}^{\prime \prime}{ }_{\max , \mathrm{TT}}$ & * & * & $0.193 \pm 0.013$ & $0.217 \pm 0.005$ & $0.212 \pm 0.004$ \\
\hline $\mathrm{G}_{\max , \mathrm{IP}}^{\prime \prime} \mathrm{G}_{\max , \mathrm{TT}}^{\prime \prime}$ & * & * & $1.07 \pm 0.08$ & $1.23 \pm 0.04$ & $1.22 \pm 0.07$ \\
\hline
\end{tabular}

Data in Table 7 indicate that the neat elastomeric matrix is isotropic, as expected. The systems with only HSAG showed an anisotropy index slightly higher than 1 only for storage moduli at small strain amplitude. It has been reported [31] that an anisotropic behavior of the rubber composite can be observed when HSAG is above its percolation threshold, and this is not the case of the material studied in this work. To account for the anisotropy index slightly higher than 1 at low strain, it could be commented that HSAG agglomerates present at rest some preferential orientation, which is disrupted by the strain application. Very similar results were obtained with the silica-filled composite. Silica aggregates are not expected to give rise to a clearly detectable anisotropy. It was reported [34] that aggregates of CB (CB N220) could show some anisotropy "in the form of a reduction of aggregate breadth, or flatness, in one direction". However, it was also reported that also perfectly spherical particles can give rise to an anisotropic behavior, if not homogeneously dispersed. The addition of HSAG, either pristine or functionalized, to the silica-based composite did not substantially modify the anisotropic behavior of the composite. However, an increase in the anisotropy index can be observed in Table 7, both at low and large strain amplitudes, as if the lamellar filler was able to provide an anisotropic behavior to the hybrid filler system.

\subsubsection{Structure of the Composite: TEM Analysis}

Transmission electron microscopy analyses were carried out on cured samples to investigate their structure on a nanoscale, focusing on filler dispersion. Attention was focused on the hybrid filler compounds containing either silica and pristine HSAG or silica and HSAG-SP. Twenty-five random micrographs were captured for each compound and different magnifications were used. In Figure 8, two representative micrographs of the two abovementioned compounds are shown.

Large agglomerates of silica are visible in the Silica/HSAG compound (Figure 8a), whereas even silica dispersions can be observed in the silica/HSAG-SP compound (Figure 8b). This behavior could be related to the interaction of silica with the graphene layers edge functionalized with SP. The structure of the compound based on HSAG-SP appears to be in line with the lower viscosity, particularly upon storage. No appreciable differences can be detected for the organization of HSAG and HSAG-SP in the two compounds. 


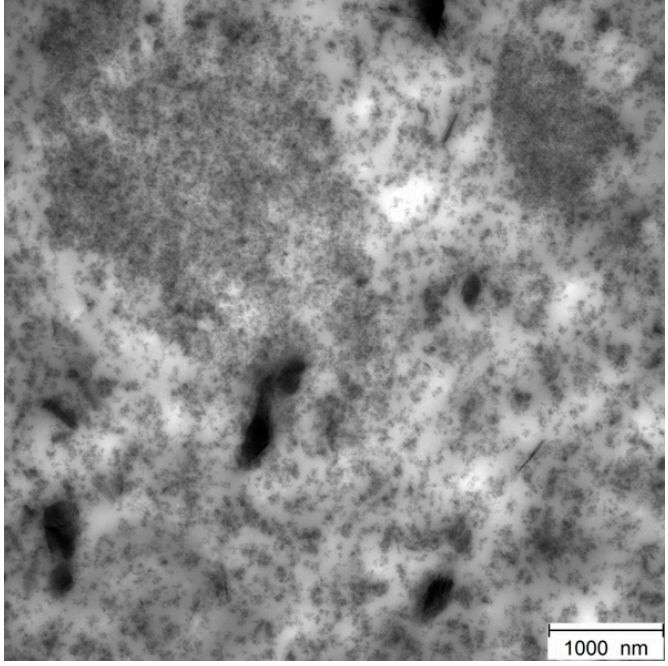

(a)

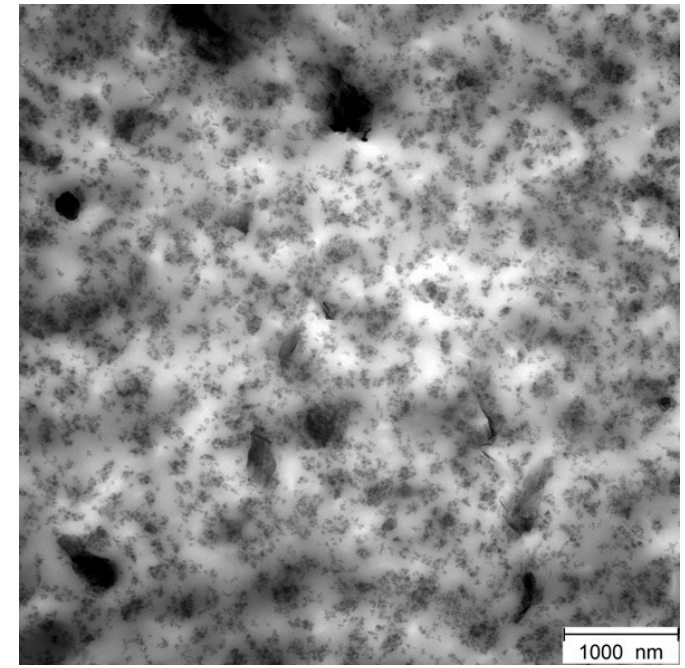

(b)

Figure 8. TEM micrographs of the Silica/HSAG (a) and Silica/HSAG-SP (b) vulcanized compounds.

\section{Overall Discussion of Results}

The results reported above show that HSAG-SP, used in place of a minor amount of silica, is able to bring about substantially the same tensile and dynamic mechanical properties as the composite with silica as the only filler, with slightly lower filler networking phenomenon, improving the rheological properties. The effect of HSAG-SP is appreciably different from that of pristine HSAG, particularly as far as the tensile properties are concerned but also considering the dynamic rigidity and the rheological properties.

A key role seems to be played by the functionalization of HSAG with SP, in particular by the location of the $\mathrm{OH}$ groups brought by SP, on the edges on the HSAG layers. The $\mathrm{OH}$ groups are able to establish an intimate interaction with silica and even a chemical bond could be hypothesized. They are, in principle, able to react with the silane TESPT. The compatibility of HSAG-SP with silica and the formation of an integrated hybrid filler system appears to be responsible for obtaining the same dynamic-mechanical and tensile properties and improving the rheological properties. In particular, the absence of polar functional groups on the basal planes of HSAG enables disruption of the silica filler network, and this could be the origin of the greater flowability.

Slightly anisotropic properties are observed in the presence of the hybrid filler system, based on either pristine or functionalized SP: dynamic moduli are only $20 \%$ higher in the IP direction than in the TT direction. This behavior appears to be due to the lamellar shape of the carbon filler, and the modification with SP does not play a role.

\section{Conclusions}

This work demonstrates that a nanosized graphite edge functionalized with $\mathrm{OH}$ groups can improve the properties portfolio of an elastomeric silica-based composite, when it is used in partial replacement of silica. The key role appears to be played by the edge functionalization, which maintains substantially unaltered basal planes of the graphitic layers and promotes their compatibilization with silica. It is thus crucial to apply a functionalization technology able to add functional groups only in a peripheral position, namely on the edges. In this work, functionalization was performed with a pyrrole compound, serinol pyrrole. The hybrid filler system silica/HSAG-SP obtained the same tensile and dynamic-mechanical properties, with remarkable improvement of the rheological behavior.

This work is a contribution to the field of the research on hybrid systems based on silica and nanofillers $[35,36]$. 
Author Contributions: Conceptualization, M.G.; methodology, S.A., S.P. and G.P.; investigation, G.P. and S.P.; resources, M.G.; writing-original draft preparation, M.G., S.A., S.P. and G.P.; review and editing, M.G., S.A., S.P. and G.P.; supervision, M.G. All authors have read and agreed to the published version of the manuscript.

Funding: This research received no external funding.

Acknowledgments: Pirelli Tire is gratefully acknowledged for the financial support of Gea Prioglio. The DIK (Deutsches Institut für Kautschuktechnologie e. V.) is acknowledged with gratitude for the technical support promptly provided.

Conflicts of Interest: The authors declare no conflict of interest.

\section{References}

1. Legrand, A.P. The Surface Properties of Silicas; Wiley: Hoboken, NJ, USA, 1998.

2. Tuel, A.; Hommel, H.; Legrand, A.P.; Chevallier, Y.; Morawski, J.C. Solid state NMR studies of precipitated and pyrogenic silicas. Colloids Surf. 1990, 45, 413-426. [CrossRef]

3. Donnet, J.-B.; Custodero, E. Reinforcement of Elastomers by Particulate Fillers. Sci. Technol. Rubber 2005, 367-400. [CrossRef]

4. Leblanc, J. Rubber-filler interactions and rheological properties in filled compounds. Prog. Polym. Sci. 2002, $27,627-687$. [CrossRef]

5. Fröhlich, J.; Niedermeier, W.; Luginsland, H.-D. The effect of filler-filler and filler-elastomer interaction on rubber reinforcement. Compos. Part A Appl. Sci. Manuf. 2005, 36, 449-460. [CrossRef]

6. Barbera, V.; Porta, A.; Brambilla, L.; Guerra, S.; Serafini, A.; Valerio, A.M.; Galimberti, M. Polyhydroxylated few layer graphene for the preparation of flexible conductive carbon paper. RSC Adv. 2016, 6, 87767-87777. [CrossRef]

7. Potts, J.R.; Shankar, O.; Du, L.; Ruoff, R.S. Processing-Morphology-Property Relationships and Composite Theory Analysis of Reduced Graphene Oxide/Natural Rubber Nanocomposites. Macromolecules 2012, 45, 6045-6055. [CrossRef]

8. Potts, J.R.; Shankar, O.; Murali, S.; Du, L.; Ruoff, R.S. Latex and two-roll mill processing of thermally-exfoliated graphite oxide/natural rubber nanocomposites. Compos. Sci. Technol. 2013, 74, 166-172. [CrossRef]

9. Galimberti, M.; Kumar, V.; Coombs, M.; Cipolletti, V.; Agnelli, S.; Pandini, S.; Conzatti, L. Filler Networking of a Nanographite with a High Shape Anisotropy and Synergism with Carbon Black in poly(1,4-cis-isoprene)-Based Nanocomposites. Rubber Chem. Technol. 2014, 87, 197-218. [CrossRef]

10. Tang, Z.; Zhang, L.; Feng, W.; Guo, B.; Liu, F.; Jia, D. Rational Design of Graphene Surface Chemistry for High-Performance Rubber/Graphene Composites. Macromolecules 2014, 47, 8663-8673. [CrossRef]

11. Luo, Y.; Zhao, P.; Yang, Q.; He, D.; Kong, L.; Peng, Z. Fabrication of conductive elastic nanocomposites via framing intact interconnected graphene networks. Compos. Sci. Technol. 2014, 100, 143-151. [CrossRef]

12. Araby, S.; Meng, Q.; Zhang, L.; Kang, H.; Majewski, P.; Tang, Y.; Ma, J. Electrically and thermally conductive elastomer/graphene nanocomposites by solution mixing. Polymer (Guildf) 2014, 55, 201-210. [CrossRef]

13. Iijima, T.; Oshima, H.; Hayashi, Y.; Suryavanshi, U.B.; Hayashi, A.; Tanemura, M. In-situ observation of carbon nanotube fiber spinning from vertically aligned carbon nanotube forest. Diam. Relat. Mater. 2012, 24, 158-160. [CrossRef]

14. Iijima, S. Helical microtubules of graphitic carbon. Nature 1991, 354, 56-58. [CrossRef]

15. Monthioux, M.; Kuznetsov, V.L. Who should be given the credit for the discovery of carbon nanotubes? Carbon 2006, 44, 1621-1623. [CrossRef]

16. Kumar, V.; Giese, U.; Hanel, T.; Giannini, L.; Galimberti, M.S. Graphene Reinforced Synthetic Isoprene Rubber based Nanocomposites. KGK. Kautsch. Gummi Kunstst. 2014, 38-46.

17. Aguilar-Bolados, H.; Brasero, J.; Lopez-Manchado, M.; Yazdani-Pedram, M. High performance natural rubber/thermally reduced graphite oxide nanocomposites by latex technology. Compos. Part B Eng. 2014, 67, 449-454. [CrossRef]

18. Xing, W.; Wu, J.; Huang, G.; Li, H.; Tang, M.; Fu, X. Enhanced mechanical properties of graphene/natural rubber nanocomposites at low content. Polym. Int. 2014, 63, 1674-1681. [CrossRef]

19. Galimberti, M.; Barbera, V.; Guerra, S.; Conzatti, L.; Castiglioni, C.; Brambilla, L.; Serafini, A. Biobased Janus molecule for the facile preparation of water solutions of few layer graphene sheets. RSC Adv. 2015, 5, 81142-81152. [CrossRef]

20. Barbera, V.; Bernardi, A.; Palazzolo, A.; Rosengart, A.; Brambilla, L.; Galimberti, M. Facile and sustainable functionalization of graphene layers with pyrrole compounds. Pure Appl. Chem. 2018, 90, 253-270. [CrossRef]

21. Barbera, V.; Bernardi, A.; Torrisi, G.; Porta, A.; Galimberti, M. Controlled functionalization of $\mathrm{sp}^{2}$ carbon allotropes for the reinforcement of diene elastomers. Elastomery 2017, 21, 235-251.

22. Barbera, V.; Brambilla, L.; Porta, A.; Bongiovanni, R.; Vitale, A.; Torrisi, G.; Galimberti, M. Selective edge functionalization of graphene layers with oxygenated groups by means of Reimer-Tiemann and domino Reimer-Tiemann/Cannizzaro reactions. $J$. Mater. Chem. A 2018, 6, 7749-7761. [CrossRef]

23. Galimberti, M.S.; Barbera, V.; Guerra, S.; Bernardi, A. Facile Functionalization of sp2 Carbon Allotropes with a Biobased Janus Molecule. Rubber Chem. Technol. 2017, 90, 285-307. [CrossRef] 
24. Prioglio, G.; Agnelli, S.; Conzatti, L.; Balasooriya, W.; Schrittesser, B.; Galimberti, M. Graphene Layers Functionalized with A Janus Pyrrole-Based Compound in Natural Rubber Nanocomposites with Improved Ultimate and Fracture Properties. Polymers 2020, 12, 944. [CrossRef] [PubMed]

25. Guerra, S.; Barbera, V.; Galimberti, M.; Giese, U. Effect of the Functionalization of graphene Nanoplatelets with a Janus Pyrrole Molecule on mechanical and electrical properties of natural Rubber Nanocomposites. Kautsch. Gummi Kunstoffe $2020,4,17$.

26. Barbera, V.; Brambilla, L.; Milani, A.; Palazzolo, A.; Castiglioni, C.; Vitale, A.; Bongiovanni, R.; Galimberti, M. Domino Reaction for the Sustainable Functionalization of Few-Layer Graphene. Nanomaterials 2019, 9, 44. [CrossRef] [PubMed]

27. Bokobza, L. Natural Rubber Nanocomposites: A Review. Nanomaterials 2019, 9, 12. [CrossRef]

28. Stankovich, S.; Dikin, D.A.; Dommett, G.H.B.; Kohlhaas, K.M.; Zimney, E.J.; Stach, E.A.; Piner, R.D.; Nguyen, S.; Ruoff, R.S. Graphene-based composite materials. Nat. Cell Biol. 2006, 442, 282-286. [CrossRef] [PubMed]

29. Pei, S.; Wei, Q.; Huang, K.; Cheng, H.-M.; Ren, W. Green synthesis of graphene oxide by seconds timescale water electrolytic oxidation. Nat. Commun. 2018, 9, 1-9. [CrossRef] [PubMed]

30. Yang, D.; Kong, X.; Ni, Y.; Ruan, M.; Huang, S.; Shao, P.; Guo, W.; Zhang, L. Improved Mechanical and Electrochemical Properties of XNBR Dielectric Elastomer Actuator by Poly(dopamine) Functionalized Graphene Nano-Sheets. Polymers 2019, 11, 218. [CrossRef] [PubMed]

31. Agnelli, S.; Pandini, S.; Torricelli, F.; Romele, P.; Serafini, A.; Barbera, V.; Galimberti, M. Anisotropic properties of elastomeric nanocomposites based on natural rubber and sp2 carbon allotropes. Express Polym. Lett. 2018, 12, 713-730. [CrossRef]

32. Agnelli, S.; Pandini, S.; Serafini, A.; Musto, S.; Galimberti, M. Anisotropic Nonlinear Mechanical Behavior in Carbon Nanotubes/Poly(1,4-cis-isoprene) Nanocomposites. Macromolecules 2016, 49, 8686-8696. [CrossRef]

33. Sheldon, R.A. Green chemistry, catalysis and valorization of waste biomass. J. Mol. Catal. A Chem. 2016, 422, 3-12. [CrossRef]

34. Gruber, T.C.; Zerda, T.W.; Gerspacher, M. 3D Morphological Characterization of Carbon-Black Aggregates Using Transmission Electron Microscopy. Rubber Chem. Technol. 1994, 67, 280-287. [CrossRef]

35. Lin, J.; Hu, D.; Luo, Y.; Zhong, B.; Chen, Y.; Jia, Z.; Jia, D. Functionalized Halloysite Nanotubes-Silica Hybrid for Enhanced Curing and Mechanical Properties of Elastomers. Polymer 2019, 11, 883. [CrossRef]

36. Staropoli, M.; Rogé, V.; Moretto, E.; Didierjean, J.; Michel, M.; Duez, B.; Steiner, P.; Thielen, G.; Lenoble, D.; Thomann, J.-S. Hybrid Silica-Based Fillers in Nanocomposites: Influence of Isotropic/Isotropic and Isotropic/Anisotropic Fillers on Mechanical Properties of Styrene-Butadiene (SBR)-Based Rubber. Polymers 2021, 13, 2413. [CrossRef] [PubMed] 